\title{
Ideology Between the Lines: Lay Inferences About Scientists' Values and Motives
}

\author{
IVAR R. HANNIKAINEN \\ Pontifical Catholic University of Rio de Janeiro \\ $\underline{\text { ivar@puc-rio.br }}$
}

\begin{abstract}
While philosophers emphasize the distinction between description and prescription, in practice people's beliefs about contentious issues seem to reflect their normative commitments. Less is known about the way that people infer others' ideology from their reports about matters of fact. In the context of scientific research on the heritability of intelligence, scientists' normative views (Study 1a) and motives (Study 2) are inferred from the evidence they report-independently of their stated research objectives. Two pre-registered replications (Studies $1 \mathrm{~b}$ and 3 ) revealed that these effects generalize to other contentious domains of behavioral and social science research. Thus, laypeople view social scientific inquiry as (partly) a guided pursuit of evidence in favor of scientists' personal ideology.
\end{abstract}

\section{Introduction}

Normative battles are often waged on factual terrain: Debates about whether we should adopt a vegetarian diet focus inordinately on empirical questions like whether our intestines are too long to properly digest meat, or archaeological evidence of how much meat our hominid ancestors really ate. Social and political movements striving toward greater equality often broadcast evidence that inequality, stereotypes, and group differences are shaped by cultural and social forces, and downplay evidence of their biological causes. Similarly, political tensions concerning abortion and climate change often turn on matters of fact and not value: at what stage a fetus feels pain, whether rising temperatures are primarily caused by human activity, and so on. Though moral philosophers emphatically distinguish description and prescription (see, e.g., Kagan, 1998; Hume, 1739; Stevenson, 1944), in numerous contexts factual claims play the part of ideological commitments.

Studies of human behavior and decision-making, characteristically concerned with what is, provide a notorious hotbed for inferences about what ought to be: Lay credence in biological accounts of gender roles (Coleman \& Hong, 2008) and political orientation (Suhay, Brandt \& Proulx, 2017) could encourage negative stereotyping and prejudice while in the 
context of sexual orientation these theories could have the reverse effect, i.e., of promoting tolerance (Haider-Markel \& Joslyn, 2008).

How and why people derive normative values from descriptive facts is not fully understood: Perhaps, chalking up group differences to biological causes may be interpreted as implying that they are 'natural' or 'normal' - which conveys not only statistical information but also encourages an inference about its moral acceptability (Bear \& Knobe, 2016). Relatedly, genetic predispositions are known to appear more immutable than social causes (Dar-Nimrod \& Heine, 2011). So, a lay belief that group differences are the product of genes instead of experience may suggest that they are not easily undone. Inferences concerning normality and immutability may in turn encourage people to adopt (what are perceived as) consonant normative attitudes.

The focus of the present work, however, is not the leap from is to ought, but its attribution to third-party agents in scientific contexts. Do people infer scientists' ideology from the evidence they report? In three studies, I investigate whether (Studies $1 \mathrm{a}$ and 1b) and why (Studies 2 and 3) scientists' evidence is seen as indicative of their normative values.

\section{General Methods}

All studies were conducted on Amazon Mechanical Turk. The sample was restricted to workers with a $90 \%$ approval rate based in the United States. I report how sample size was determined, all data exclusions, all manipulations, and all measures in each study. Data and materials are publicly available on the Open Science Framework at: https://osf.io/upkjf/.

Since I was not interested in inferences that arise from problem selection (i.e., the choice of a research question), every scientist investigates two kinds of explanations for human behavior: one congenial explanation-according to which human behavior and capacities are malleable by extrinsic causes (experience, education, and social and developmental pressures); and one uncongenial explanation-according to which human behavior and capacities are predicted by intrinsic, biological characteristics (genotype, neural structures and hormones). Thus, the scientist's research question and hypotheses were held constant across conditions.

The purpose of the present work is to understand how a study's outcome-i.e., its findings-influence the authoring scientist's perceived ideology. Throughout the studies below, in a series of between-subjects designs, two scientists conduct the same study but find opposite results (i.e., support for either extrinsic or intrinsic causal explanations).

\section{Study 1a: Inferences about descriptive beliefs and normative views}

Study 1a examines the effect of an intelligence researcher's findings on his ascribed beliefs and worldview. In the Experience condition, education and mental effort exerted considerable effects on intelligence and intelligence was weakly heritable. In the Genetics 
condition, intelligence is found to be strongly heritable while education and effort play a minimal role.

\subsection{Methods}

\subsubsection{Sample size estimation}

I sought to recruit 100 participants per condition, which-according to a sensitivity power analysis, setting $\alpha$ to .05 - suffices to detect an effect of Cohen's $d=0.40$ with $80 \%$ power.

\subsubsection{Participants and procedure}

208 participants $(41 \%$ female; age mean $=35$ years) took part in Study 1a. Participants were presented with the hypothetical case of Dr. Karlsson, an intelligence researcher. His research program is briefly introduced, and participants were then randomly assigned to one of two conditions: Experience or Genetics.

Table 1. Stimuli: Results of intelligence research in Study 1. Italicized content varies by condition.

\section{Experience}

As it turns out, Karlsson found an intriguing pattern of results: The strongest predictors of performance were educational attainment, and the length and ratio of effort-topause. Together these factors predicted over $26 \%$ of people's responses. Individuals with higher educational attainment provided the most correct answers on the arithmetic, mental rotation, and semantic memory tasks. In addition, participants' approaches to mental exercise also strongly influenced success: Long stretches of focused attention (around 4 minutes), alternated with adequate pauses (around 40 seconds) improved performance.

In contrast, genetic variability explained only $4 \%$ of answers. Even among twins with identical genotypes, large differences in math and linguistic ability were found.

Since its publication, Karlsson's work has attracted much attention from the media, and elicited varied responses from colleagues. "We believe this is an interesting result! Our findings indicate that, contrary to certain previous assumptions, basic cognitive capabilities - mental rotation, math and language really depend fundamentally on effort and education," said Dr. Karlsson.

"Pace is really important - the precise ratio of work to rest is a critical step in managing dopamine re-uptake, which may facilitate sustained attention during demanding tasks. In any case, genetics really seem to be playing a minor role. Within genetically-identical twin pairs, we observe huge performance gaps, with the drop-outs doing much worse than the graduates. Similarly, those who paid focused attention and then took short mental breaks between bursts of attention did noticeably better."

"This is all I have time for today. Best of luck!", Dr.

\section{Genetics}

As it turns out, Karlsson found an intriguing pattern of results: Focusing on the arithmetic and linguistic sections, genetics predicted over $26 \%$ of people's responses. Namely, individuals with a long allele of the 4-GTTLR gene got more right answers on the arithmetic, mental rotation, and semantic memory tasks than did individuals with the short version of the gene.

In contrast, educational attainment explained only $4 \%$. Similarly, time spent on the arithmetic and linguistic tasks did not significantly predict performance.

Since its publication, Karlsson's work has attracted much attention from the media, and elicited varied responses from colleagues. "We believe this is an interesting result! Our findings indicate that, contrary to certain previous assumptions, basic cognitive capabilities - mental rotation, math and language really have a strong heritable component. Intelligence in adulthood seems to be predicted by genes early in life," said Dr. Karlsson.

"Considering what we know about the role of 4-GTTLR in brain function, this makes a lot of sense. A long allele fosters smaller and steadier dopamine re-uptake, which may predispose individuals to more sustained attention during demanding tasks. Clearly though, future work is necessary to uncover how this particular gene shapes our brain development. In any case, what we find is that things like education and effort play a small role once you take into account the role of genetics".

"This is all I have time for today. Best of luck!", Dr. Karlsson said. Karlsson said. 
After reading the description of Dr. Karlsson's results (see Table 1), participants were asked to indicate how likely it is that Dr. Karlsson would agree with two sets of statements, on a five-point scale ranging from 1: "very unlikely" to 5: "very likely".

Four statements were descriptive claims capturing nativist (e.g., "Some are born with more abilities than others.") versus blank-slate (e.g., "No group of people is innately more skilled - we are all essentially equal.") beliefs about human capacities. Five other statements were normative claims about whether people deserve equal treatment or not (see Table 2). Two coders achieved perfect agreement classifying scale items as either descriptive or normative in an intercoder reliability check (Cohen's $\kappa=1$ ).

If inferences about scientists' worldview are based merely on what they choose to research, we should observe no difference in Dr. Karlsson's normative views. If instead the reported evidence also shapes inferences about scientists' views, one should observe a difference in Dr. Karlsson's perceived normative values by condition.

\subsection{Results}

Mean response to each item by condition is displayed in Table 2.

Table 2. Participants' ratings of Dr. Karlsson's views in Study 1: Means and standard deviations (in brackets) for each scale item by condition. An asterisk indicates reverse-scoring.

Experience Genetics

\begin{tabular}{|c|c|c|c|}
\hline & Descriptive & & \\
\hline $1^{*}$ & It's a fact that some people have more of a chance in life than others. & $3.31(1.14)$ & $4.01(0.88)$ \\
\hline $2 *$ & By nature, some people are luckier than others. & $2.61(1.14)$ & $3.65(1.07)$ \\
\hline 3 & No group of people is innately more skilled - we are all essentially equal. & $3.26(1.13)$ & $2.50(1.17)$ \\
\hline \multirow[t]{2}{*}{$4^{*}$} & Some are born with more abilities than others. & $2.81(1.13)$ & $4.26(0.82)$ \\
\hline & Normative & & \\
\hline $1^{*}$ & People's status in society should correspond with their natural ability. & $2.52(1.09)$ & $3.17(1.05)$ \\
\hline 2 & $\begin{array}{l}\text { I believe people and social groups should be treated equally, independently } \\
\text { of ability. }\end{array}$ & $3.68(1.01)$ & $3.49(1.03)$ \\
\hline $3^{*}$ & $\begin{array}{l}\text { Some people should be treated as superior to others, given their hard-wired } \\
\text { talent. }\end{array}$ & $2.17(1.06)$ & $2.84(1.17)$ \\
\hline $4^{*}$ & $\begin{array}{l}\text { It's OK if society allows some people to have more power and success than } \\
\text { others - it's the law of nature. }\end{array}$ & $2.30(1.11)$ & $3.14(1.14)$ \\
\hline \multirow[t]{2}{*}{5} & Society should strive to level the playing field, to make things just. & $3.32(1.09)$ & $3.16(1.12)$ \\
\hline & Filler & & \\
\hline 1 & $\begin{array}{l}\text { Twin studies allow us to differentiate the effect of genes from others, like } \\
\text { education and experience. }\end{array}$ & $3.82(0.96)$ & $4.11(0.81)$ \\
\hline 2 & Intelligence is largely dependent on genetics. & $2.31(1.14)$ & $3.94(0.94)$ \\
\hline 3 & Intelligence is largely dependent on effort and education. & $4.08(1.04)$ & $2.73(1.23)$ \\
\hline
\end{tabular}


As expected, participants' ascribed more nativist beliefs $(\alpha=.75)$ to the scientist if he reported that intelligence is heritable $(\mathrm{n}=109, \mathrm{M}=2.12, \mathrm{SD}=0.59)$, and more blank-slate beliefs if he revealed that personal effort and education boost intelligence ( $n=99, M=3.13$, $\mathrm{SD}=0.83)$, Welch's $t(175.2)=9.99, p<.001, d=1.15$ [0.93, 1.38].

But, did participants also infer Dr. Karlsson's normative views from his empirical report? Indeed, the scientist's normative views $(\alpha=.69)$ were perceived to differ by condition: Participants attributed more egalitarian views if his evidence indicated that experience shapes human intelligence $(\mathrm{n}=99, \mathrm{M}=3.63, \mathrm{SD}=0.68)$ and more reactionary views if he reported on the heritability of intelligence $(\mathrm{n}=109, \mathrm{M}=3.09, \mathrm{SD}=0.69)$, Welch's $t(225.1)=5.65, p<$ $.001, d=0.73[0.48,0.99]$. Importantly, this was the case even though the scientist's research question and methods were constant across conditions - the difference lied only in his reported results.

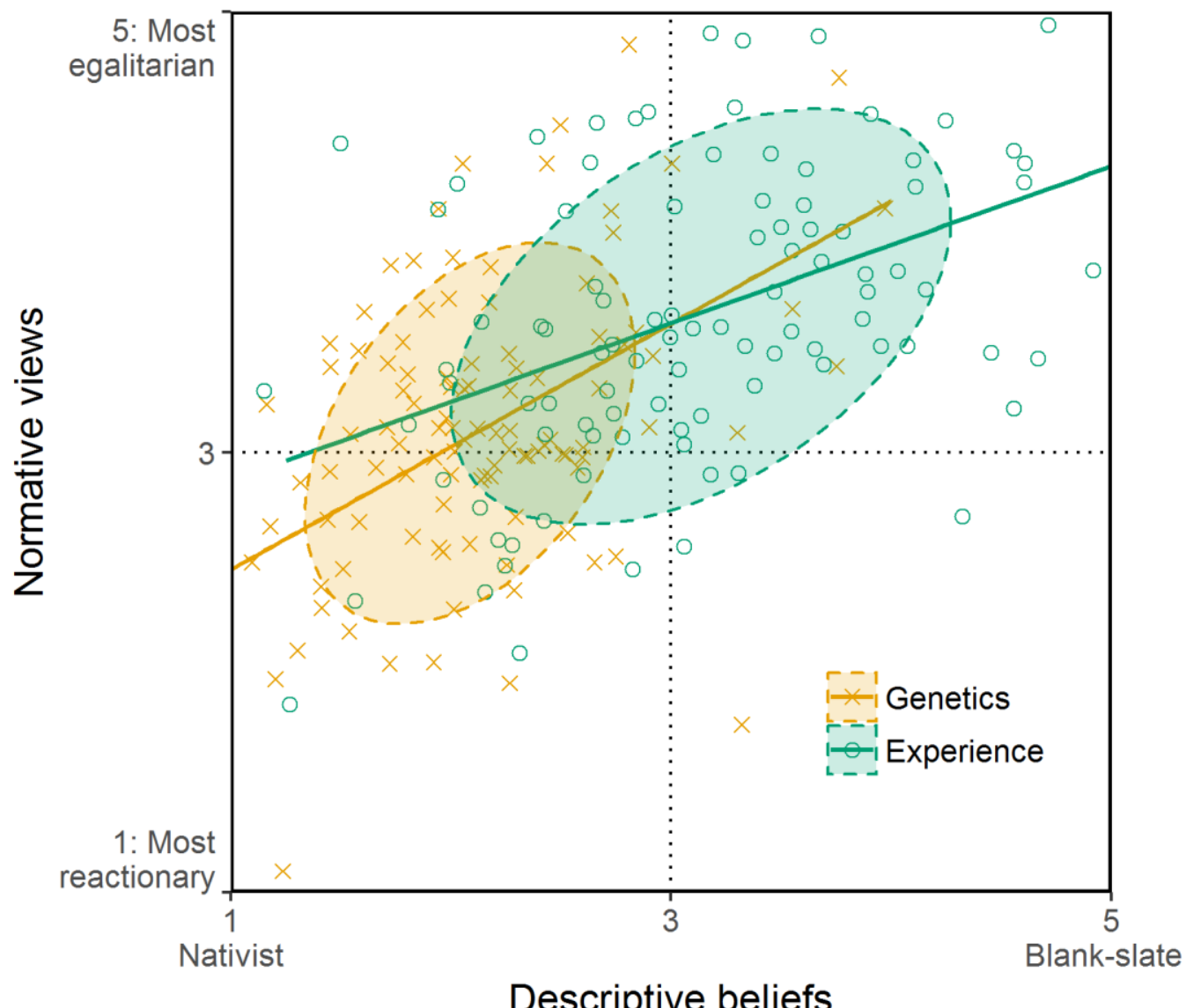

Figure 1. Descriptive-belief and normative-view ascriptions by experimental condition. Shaded ellipses enclose the $70 \%$ confidence interval of the condition means.

Descriptive beliefs and normative views strongly correlated in both conditions: r(Effort) $=.44, n$ (Genetics) $=.48, p s<.001$ (see Figure 1$)$. The more a participant believed that the scientist held blank-slate (versus nativist) beliefs about human intelligence, the more that participant also believed the scientist espoused egalitarian normative values.

In a two-way ANOVA the effect of condition on descriptive-belief ascriptions was larger than its effect on normative-value ascriptions (ascription-type $\times$ condition interaction 
$F(1,206)=21.00, p<.001)$. Thus, it stands to reason that participants might have been inferring Dr. Karlsson's normative values from his ascribed descriptive beliefs.

Using the mediation package (Tingley et al., 2014) in $R 3.4 .0$, I conducted a mediation analysis with condition as treatment variable and descriptive-belief attributions as mediator of the effect on normative-view attributions. Estimates were calculated based on 5000 simulations using the quasi-Bayesian Monte Carlo method (Imai, Keele \& Tingley, 2010). As expected, the effect of condition on normative values was strongly mediated (prop. mediated $=0.75[0.44,1.28])$ by ascribed descriptive beliefs, $\mathrm{ACME}=0.37[0.24,0.52], p<.001$, rendering the direct effect non-significant, $\mathrm{ADE}=0.12[-0.09,0.34], p=.27{ }^{1}$ Therefore, participants appeared to infer Dr. Karlsson's descriptive beliefs from his evidence, and-from his descriptive beliefs - the normative views he is likely to espouse.

\section{Study 1b: Pre-registered replication and extension}

Study $1 \mathrm{~b}$ extends this finding in three new directions. First, I examine whether normative-value ascriptions emerge for other research questions: gender differences in mating strategy, and the prediction of violent behavior. Second, I test whether scientific evidence also shapes a hypothetical reader's normative views, and even participants' own views. Third, this time, the scientist's hypotheses and findings are described but their reaction to the findings is omitted.

\subsection{Methods}

\subsubsection{Sample size estimation}

Since the effect of evidence upon normative attitudes was larger than expected, I planned to recruit 50 participants per cell. A sensitivity power analysis for between-subjects ANOVA, recommended a sample size of 277 to detect an effect of Cohen's $f=.20$ (or $d=$ 0.40 ) with $80 \%$ power.

\subsubsection{Participants and procedure}

317 participants ( $47 \%$ female; age mean $=37$ years) took part in Study $1 \mathrm{~b}$. In a $2 \times 3$ between-subjects design, participants were randomly assigned to either the Extrinsic or Intrinsic condition, and one of three research domains, Intelligence, Mating-Strategy, or Violence.

In the Extrinsic condition, the scientists' findings pointed towards effects of education and nutrition (Intelligence), socialization and culture (Mating-Strategy), and parenting and development (Violence). In the Intrinsic condition, the scientists' findings pointed toward effects of genetics (Intelligence; Violence), hormones and neurochemistry (Mating-Strategy). For each domain and evidence condition, three versions of the stimuli were created with minor variations in wording (e.g., scientist name and gender).

\footnotetext{
${ }^{1}$ As expected, the reverse mediation model (with normative-views attributions mediating the effect of descriptivebeliefs attributions) revealed a weaker indirect effect, $\mathrm{ACME}=0.23[0.13,0.35]$, and a stronger direct effect, $\mathrm{ADE}$ $=0.68[0.49,0.86]$, prop. mediated $=0.25[0.15,0.38], p \mathrm{~s}<.001$.
} 
Participants were then asked to consider two normative statements (see Table 3), and report whether the scientist agrees with the egalitarian (labeled A) or the reactionary (labeled B) statement, using a sliding scale from 10: "believes A", 0: "A and B equally", -10: "believes B". On the same scale, participants then reported their own views, and those of "others who learn about [the scientist]'s research".

Table 3. Stimuli: Egalitarian and reactionary statements in Study $1 b$ (for each research domain).

\begin{tabular}{|c|c|c|}
\hline & Egalitarian view & Reactionary view \\
\hline Intelligence & $\begin{array}{l}\text { People and social groups should be treated } \\
\text { equally, independently of ability. }\end{array}$ & $\begin{array}{l}\text { Some people are simply more likely to } \\
\text { excel and succeed, and thus should be } \\
\text { treated as superior. }\end{array}$ \\
\hline Mating Strategy & $\begin{array}{l}\text { Cheating is morally wrong. It should be } \\
\text { seriously condemned in men and women } \\
\text { alike. }\end{array}$ & $\begin{array}{l}\text { Although it is wrong to cheat, men should } \\
\text { be cut some slack for cheating. }\end{array}$ \\
\hline Violence & $\begin{array}{l}\text { Given what the science of criminal } \\
\text { behavior shows, society should treat } \\
\text { criminals with sympathy and compassion. }\end{array}$ & $\begin{array}{l}\text { Given what the science of criminal } \\
\text { behavior shows, it is best to punish } \\
\text { criminals severely. }\end{array}$ \\
\hline
\end{tabular}

Lastly, participants provided demographic information and completed an attention check. Planned methods, experimental predictions and an analysis plan were pre-registered at https://aspredicted.org/74sf7.pdf. More participants failed the attention check $(n=73)$ than expected, resulting in a smaller sample size $(N=244)$ than planned.

\subsection{Results}

Below I report two analyses that were registered prior to data collection: a confirmatory analysis generalizing the findings of Study 1a (Section 4.2.1), and a novel, exploratory analysis (Section 4.2.2).

Results were analyzed using linear mixed effect models, with condition as a fixed factor and version nested within domain as random factors.

\subsubsection{Planned confirmatory analysis}

As predicted, perceptions of scientists' ideology was influenced by reported evidence, $B=2.28$ [1.03, 3.53], $z=3.58, p<.001$. Replicating Study 1a, scientists were perceived as more egalitarian when they reported on extrinsic, $M=-1.82$ [-2.62, -1.01], than intrinsic, $M=$ $0.47[-0.49,1.42]$, causes of human behavior (see Fig. 2).

\subsubsection{Planned exploratory analyses}

A corresponding model predicting the normative views ascribed to a reader "learning about the scientists' evidence" revealed an effect of evidence-type, $B=1.78$ [0.65, 2.91], $z=$ $3.10, p=.002$. The effect on participants' own views was not significant, $B=1.21[-0.12$, 2.55], $z=1.78, p=.074$. 


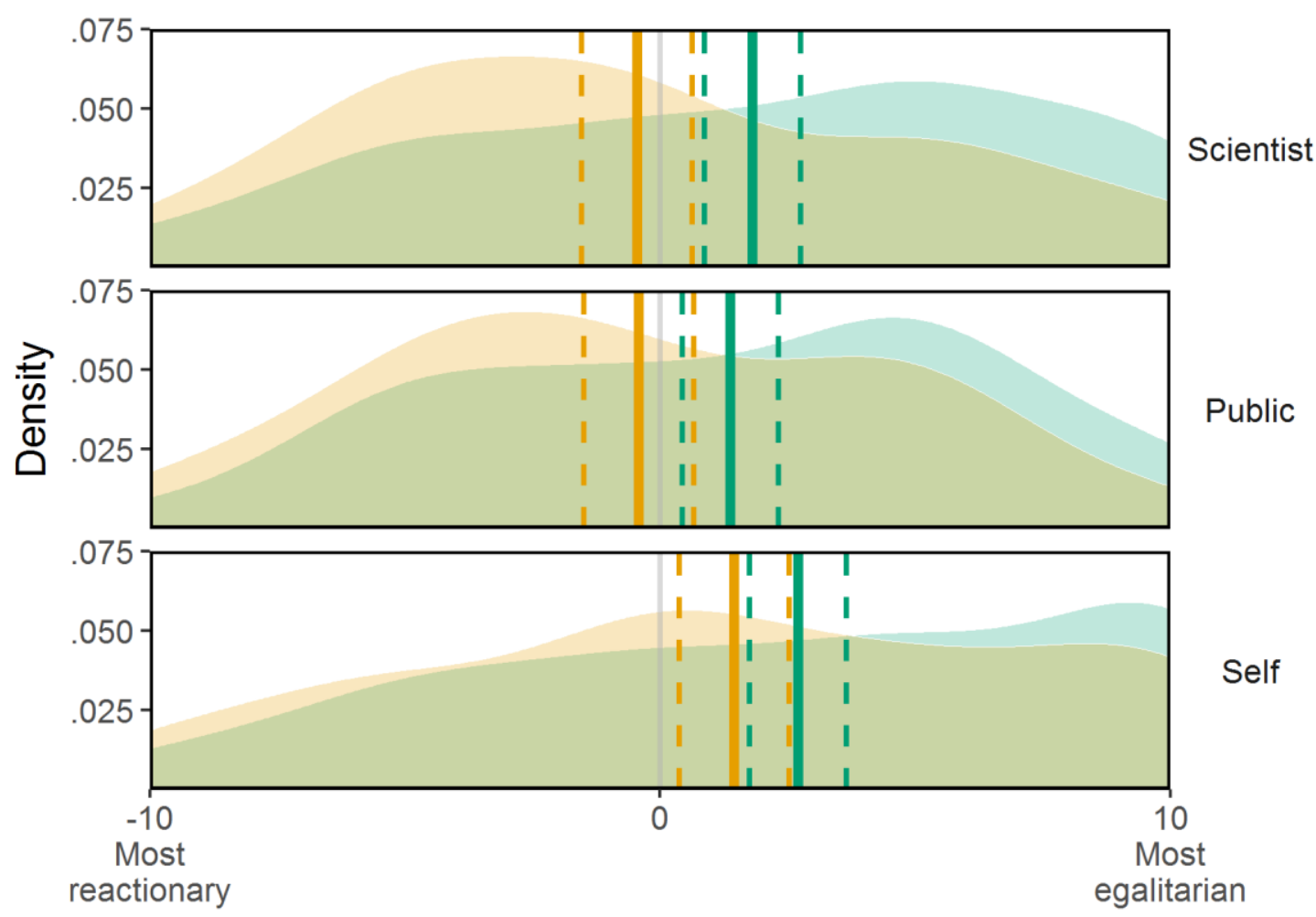

Normative views

Figure 2. Density curve of normative views by evidence-type for Scientist, Public and Self. Predicted means (solid) and $95 \%$ confidence intervals (dashed) by evidence-type are displayed using vertical lines.

\subsection{Discussion}

In the first pair of studies, scientists who provided intrinsic explanations for human behavior and capacities (citing genetic and biological causes) were perceived as more reactionary than scientists who provided extrinsic explanations (citing social and environmental causes).

This result cannot be attributed to differences in the researchers' stated objectives-since they conducted the same study to examine both intrinsic and extrinsic hypotheses-nor does it stem from their reaction to the findings. Rather, the inference appears to result from the evidence that the scientist obtained and reported.

Participants also reported that the readership would become more reactionary after learning about the scientists' uncongenial evidence (relative to the congenial evidence). Meanwhile, the effect on participants' own normative views was not significant: Participants themselves remained in agreement with the egalitarian view regardless of condition. These findings dovetail with past literature demonstrating a bias blind spot (Pronin, 2007; Pronin, Lin \& Ross, 2002) - the tendency to represent oneself as uniquely immune to flawed reasoning. 


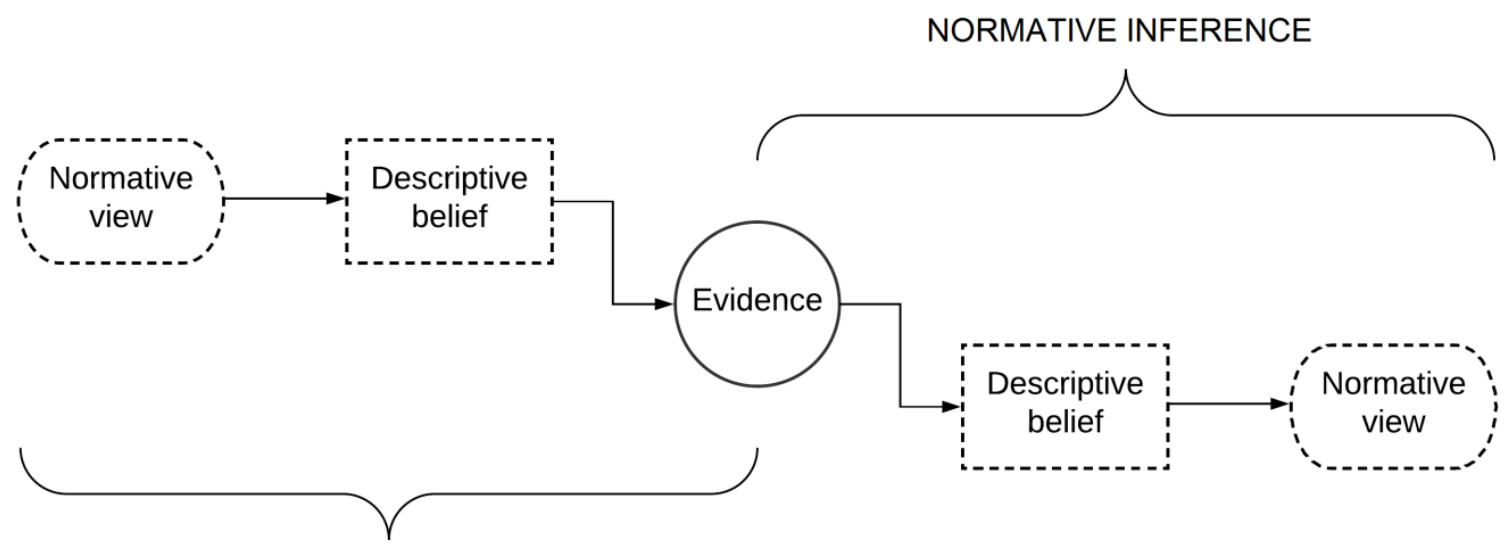

VALUE-DRIVEN SCIENCE

Figure 3. Value-driven science and normative inference models.

Is the scientist's ideology considered a consequence of their evidence (normative inference model) or the motor behind their search for evidence (value-driven science model; see Figure 3)? In the remaining sections, I attempt to answer this question through two further experiments.

\section{Study 2: Accuracy versus directional motives}

Research in motivated reasoning reveals two primary motives for retrieving and processing information (Kunda, 1990): accuracy goals, by which people seek to form true beliefs, and directional goals, when agents search for information in support of a desired conclusion.

The Normative Inference and Value-Driven Science models differ in the extent to which they represent directional reasoning as shaping scientific evidence: According to the Value-Driven Science model, researchers seek out in support of their preferred conclusions. Thus, their research reports what they were "trying to prove". By contrast, the Normative Inference model does not imply the desire to corroborate a particular hypothesis-since normative values are the consequence, and not the cause, of the empirical evidence.

\subsection{Methods}

\subsubsection{Sample size estimation}

I planned to recruit 80 participants per cell. To detect the effect of evidence-type on directional motives, a power analysis for one-way ANOVA with three conditions, recommended a sample size of 244 participants to detect an effect of Cohen's $f=.20$ (or $d=$ 0.40 ) with $80 \%$ power and $\alpha$ at .05 .

\subsubsection{Participants and procedure}

243 participants $(38 \%$ female; age mean $=34$ years) were invited to take part in Study 2 . After providing informed consent, participants were randomly assigned to one of three 
conditions-Genetics, Experience, or No Results-and read about Dr. Karlsson's research, reusing the materials developed in Study 1a.

In order to distinguish attributions of accuracy and directional motives, two questions concerning each of the hypotheses of interest were asked. Using five-point scales anchored at 1: "Strongly disagree", 3: "Neither agree nor disagree", and 5: "Strongly agree", participants reported whether Dr. Karlsson wants/wanted to "know whether" and "prove that":

$\left(\mathrm{H}_{1}\right)$ people's genetic make-up predicts their future intelligence.

$\left(\mathrm{H}_{2}\right)$ education and persistence can substantially improve people's intelligence.

\subsection{Results}

In paired $t$-tests for each hypothesis and condition, Dr. Karlsson was perceived as wanting to "know" more than to "prove", all $p$ s $<.001$ (see Table 4). Still, one-sample $t$-tests against the midpoint revealed that the scientist was also viewed as wanting to prove certain hypotheses-i.e., both hypotheses in the NoEvidence condition $\left(H_{1}\right.$ vs. $\mu=3: d=0.36 ; H_{2}$ vs. $\mu$ $=3: d=0.28)$, and the hypothesis that received empirical support in the Genetics $\left(H_{1}\right.$ vs. $\mu=3$ : $d=0.65)$ and Experience $\left(H_{2}\right.$ vs. $\left.\mu=3: d=0.27\right)$ conditions, all $p s<.05$.

Table 4. Participants' ratings of Dr. Karlsson's motives in Study 2: Means and standard deviations (in brackets) for each scale item by condition.

\begin{tabular}{llccc} 
& & No Results $(\mathrm{n}=97)$ & Experience $(\mathrm{n}=78)$ & Genetics $(\mathrm{n}=87)$ \\
\hline Know whether... & $\mathrm{H}_{1}$ : Genetics & $4.22(0.87)$ & $4.23(0.72)$ & $4.49(0.63)$ \\
& $\mathrm{H}_{2}$ : Experience & $4.00(0.98)$ & $4.16(0.88)$ & $3.63(1.31)$ \\
\hline Prove that... & $\mathrm{H}_{1}$ : Genetics & $3.37(1.07)$ & $2.88(1.30)$ & $3.74(1.14)$ \\
& $\mathrm{H}_{2}$ : Experience & $3.32(1.12)$ & $3.35(1.30)$ & $2.72(1.25)$ \\
\hline
\end{tabular}

\subsubsection{Did study findings predict the scientists' ascribed goals?}

I conducted separate $2 \times 3$ repeated-measures ANOVAs predicting accuracy and directional motives, with hypothesis, experimental condition, and the hypothesis $\times$ condition interaction as predictors.

Of the two hypotheses, participants tended to perceive that Dr. Karlsson was more motivated to prove $\mathrm{H}_{1}$ (i.e., that intelligence has a genetic basis), hypothesis $F(1,257)=25.58$, $p<.001$, although this perception varied by experimental condition, hypothesis $\times$ condition $F(2$, $257)=10.42, p<.001$. Corresponding effects of hypothesis, $F(1,257)=5.39, p=.021$, and of the hypothesis $\times$ condition interaction, $F(2,257)=24.14, p<.001$, on ratings of whether the scientist wanted to "know whether" a hypothesis obtained were also observed.

Next, I conducted tests of simple effects with No Results as the reference level to ascertain the direction and magnitude of between-condition differences. When Dr. Karlsson found that genetics predicted intelligence, he was perceived as more motivated to prove $\mathrm{H}_{1}$, Welch's $t(177.9) t=2.13, p=.035, d=0.31$, and less motivated to prove $\mathrm{H}_{2}$, Welch's $t(173.7)=$ 
$-3.38, p<.001, d=-0.49$, than before he obtained evidence. After reporting that education and effort predicted intelligence, Dr. Karlsson was perceived as less motivated to prove $\mathrm{H}_{1}$, Welch's $t(149.2)=-2.75, p=.007, d=-0.42$, but no more motivated to prove $\mathrm{H}_{2}$, Welch's $t(153.1)=$ $0.14, p=.89, d=0.02$, than before obtaining any evidence.

Thus, evidence appeared to retrospectively shift participants' inferences about what the scientist "wanted to prove" toward the obtained result and/or away from the other hypothesized effect.

5.2.2. Was the evidence of a genetic basis of intelligence perceived as more motivated than the evidence for effects of effort and education?

To examine this question, hypotheses in the Experience and Genetics conditions were recoded as either: (1) supported or (0) unsupported (e.g., in the Genetics condition $H_{1}$ was supported and $H_{2}$ was unsupported).

A repeated-measures ANOVA predicting whether Dr. Karlsson was perceived as motivated to prove the supported (relative to unsupported) hypothesis with support, condition and the support $\times$ condition interaction revealed the expected effect of $\operatorname{support}, F(1,161)=41.6, p$ $<.001$. In addition, the support $\times$ condition interaction was observed, $\mathrm{F}(1,161)=5.79, p=$ .017 -indicating that, while the scientist was perceived as trying to prove what he found more than what he did not find, this difference was significantly larger when the evidence favored the genetic explanation: Experience $t(77)=-2.97, p=.004, d=-0.34 ;$ Genetics $t(86)=6.13, p<$ $.001, d=0.66$.

\subsection{Discussion}

Overall, participants ascribed accuracy goals (wanting to "know whether") more than they ascribed directional goals (wanting to "prove that"). Still, scientists' evidence was viewed as reflecting what they "wanted to prove".

This effect was stronger when results revealed that intelligence is heritable versus the more congenial finding that education and effort can make one more intelligent-an asymmetry that dovetails with research on the influence of moral considerations on evaluations of the quality of scientific research (Colombo, Bucher, \& Inbar, 2016).

\section{Study 3: Normative Inference versus Value-Driven Science models}

Study 2 yielded indirect support for the value-driven view of science: Scientists were perceived as selectively motivated to prove the hypothesis that their results favored-implying a pre-existing motive.

In Study 3, scientists are interviewed about normative issues both early on in their careers and after publishing their findings. An effect of evidence-type on early-career interviews would indicate that scientists who report divergent findings are perceived as differing in their prior ideology—as specified by the Value-Driven Science model. 
By comparing ideological differences before and after the evidence is gathered, Study 3 also assesses the Normative Inference model. An increase in the effect of evidence-type on normative values after the findings are published (relative to early on in the scientist's career) would suggest that scientists are viewed as drawing a normative inference too.

\subsection{Methods}

\subsubsection{Sample size estimation}

I planned to recruit 250 participants. A sensitivity analysis for a between-subjects, twoway ANOVA revealed that the study was adequately powered (80\%) to detect an effect of condition greater than or equal to Cohen's $f=.25$ (or $d=0.50$ ) with $\alpha$ set to .05 .

\subsubsection{Participants and procedure}

301 participants $(47 \%$ female; age mean $=36$ years $)$ took part in Study 3. In a 2 (time: antecedent, recent) x 2 (evidence: intrinsic, extrinsic) between-subjects design, participants read about a scientist's work as in Study $1 b$. Scientific domain was treated as a random effect.

After reading about a scientist's hypotheses and results, participants were told about the scientist's participation in an interview or panel discussion, which took place either "earlier on in their career" (Past condition) or "in the weeks after publishing their findings" (Recent condition).On a 20-point scale, anchored at 10: "Almost certainly A", 5: "A more likely than B", 0: "Both equally/I don't know", -5 : "B more likely than A", and -10: "Almost certainly B", participants were asked to imagine the scientist's answer to a panelist/journalist's question, with higher (/lower) scores corresponding to characteristically egalitarian (/reactionary) views.

In order to ascertain whether the primary finding in Study 2 generalized to other research domains, next, participants were asked whether the scientist conducted the study to "know whether" and/or "prove that" each hypothesis obtained, on separate five-point scales. On the final page, participants provided demographic information-including two political orientation items in order to examine whether the strength of inferences about values and motives depends upon participants' own ideology.

Planned methods, predictions and an analysis plan were pre-registered at https://aspredicted.org/jp7fv.pdf. More participants failed the attention check than expected (observed $n=68$ vs. expected $n \approx 50$ ), resulting in a final sample size of 233 (vs. planned $N \approx$ 250).

\subsection{Results}

Two pre-registered analyses (Section 6.2.1), and an unplanned analysis (Section 6.2.2) were conducted.

Results were analyzed using linear mixed effect models, with evidence-type, interviewtime, and their interaction as fixed effects, and domain as random effect.

\subsubsection{Pre-registered analyses}


Past and recent views. As predicted, there was an effect of evidence-type on scientist's past worldview, such that scientists who reported extrinsic evidence were perceived as more egalitarian even earlier on in life, $B=3.03[1.10,4.96], z=3.07, p=.002$. Replicating Study $1 b$, the effect on scientists' actual worldview was also significant, $B=4.14[1.89,6.39], z=$ $3.61, p<.001$.

Entering interview-time and the interview-timexevidence-type interaction into the mixed-effects model did not reveal a significant interaction term, $B=1.11[-1.84,4.06], z=$ $0.74, p=.46$ (see Figure 4). Thus, the effect of evidence-type on normative views appears to arise as participants attribute a pre-existing ideology - rather than merely by thinking that scientists update their normative worldview in light of their empirical findings.

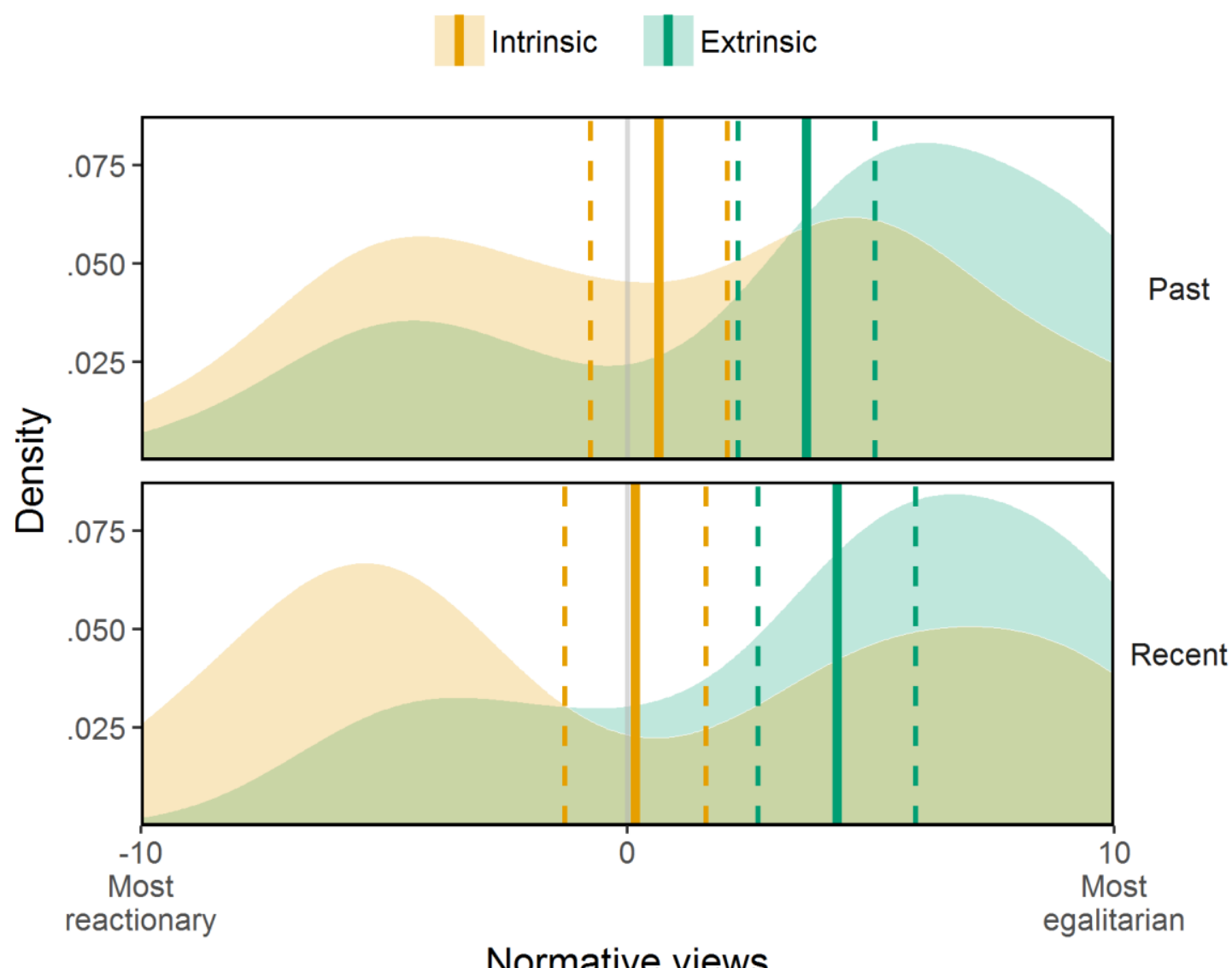

Figure 4. Density curve of normative views by evidence-type and interview time. Predicted means (solid) and $95 \%$ confidence intervals (dashed) by evidence-type are displayed using vertical lines.

Accuracy and directional motives. As in Study 2, scientists were perceived as wanting to "know whether" their predictions obtain more than wanting to "prove" them, all $p s<.005$. To investigate whether participants viewed scientists as motivated to report the observed result, directional motives were coded as either (1) supported or (0) unsupported. Consistent with the Value-Driven Science view, scientists were seen as wanting to prove what they found more than what they did not find (as revealed by a main effect), $B=0.91[0.64,1.18], z=6.61$, $p<.001$. 
I also predicted that the effect of support would be larger for intrinsic evidence-such that scientists reporting uncongenial, intrinsic evidence would be seen as more directionallymotivated than scientists reporting congenial, extrinsic evidence. This prediction was not borne out: The effect of support was no larger for intrinsic evidence than for extrinsic evidence, $B=0.28[-0.10,0.65], z=1.45, p=.15^{2}$

\subsubsection{Unplanned analyses: political orientation.}

In exploratory analyses, I examined whether beliefs about scientists' values and motives are moderated by participants' own political orientation.

Looking at supported hypotheses, conservatives were more likely than liberals to view scientists as motivated to prove that extrinsic causes shape human behavior, $B=0.40[0.19$, $0.60], z=3.80, p<.001$ - but this was not true of intrinsic causes, $B=0.14[-0.06,0.35], z=$ $1.35, p=.18$ (see Figure 5A).

Although inferences about scientists' normative views appeared to vary along the political spectrum (see Figure 5B), the interaction between evidence-type and political orientation did not reach statistical significance, $B=-1.40[-2.88,0.80], z=-1.85, p=.064$.

A

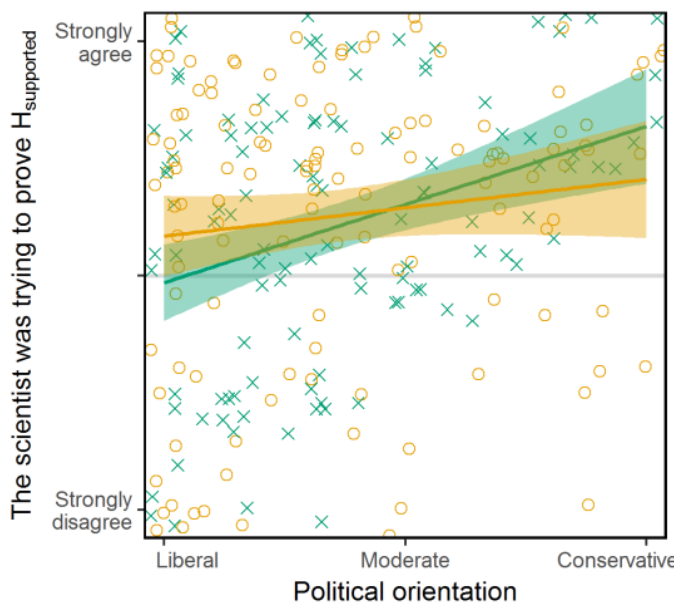

B

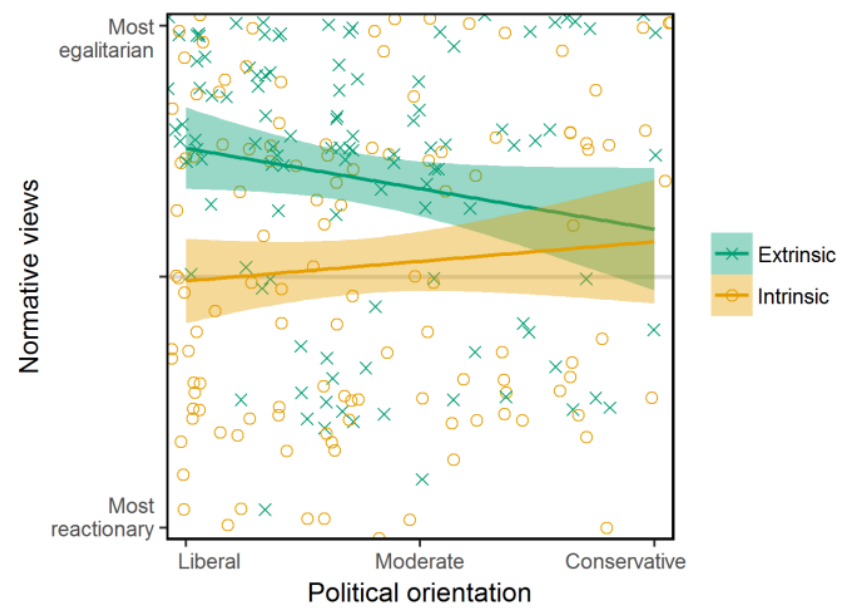

Figure 5. Scatter plot and linear trend line of scientists' (A) motives and (B) normative views by evidence-type and participants' political orientation. Random jitter has been added to aid visualization.

\subsection{Discussion}

Study 3 drew support for the Value-Driven Science model: The manipulation of scientists' reported evidence influenced perceptions of the normative ideals that the scientist would have held even before they conducted the study. The difference in scientists' ascribed values after obtaining the evidence was only slightly (and non-significantly) larger. As a result, whether participants are also attributing a normative inference is unclear. Thus, the predominant mechanism accounting for perceptions about scientists' worldview appears to be the backward inference that their evidence reveals a pre-existing ideology.

\footnotetext{
${ }^{2}$ In an unplanned analysis, relaxing exclusion criteria - by including participants who failed to recall the study's conclusion $(n=50)$ but correctly recalled its research question $(n=18)$-rendered the interaction significant, $B=$ 0.44 [0.11, 0.78], $z=2.58, p=.010$.
} 
The effect of empirical support on directional motives generalized to a broader set of domains but, unlike Study 2, no interaction with evidence-type was observed.

Reactions toward science in general (Rutjens, Sutton, \& van der Lee, 2017), and intrinsic causal explanations for human behavior in particular, may depend on participants' own political outlook (Nisbet, Cooper, \& Garrett, 2015; Washburn \& Skitka, 2017). Exploratory tests also revealed that, while scientists reporting evidence of intrinsic causes were perceived as equally value-driven by liberals and conservatives, conservatives viewed extrinsic explanations as more value-driven than did liberals. So, while conservatives revealed a general skepticism of the objectivity of social science (see also Gauchat, 2012), liberals' skepticism appeared to depend on the type of evidence. This asymmetry dovetails with recent evidence that liberals are also motivated to reject discordant scientific messages (Washburn \& Skitka, 2017), such as reports of group differences that appear to threaten an egalitarian worldview (Winegard, Clark \& Hasty, 2018). Still, it is important to reiterate that these results were not specifically predicted.

\section{General Discussion}

In the context of social and behavioral science research, inferences about scientists' normative views-concerning how things should be-are made on the basis of the content of their empirical reports-concerning how things are. For instance, reports of personal control over intelligence (via education and effort) were seen as indicative of the authoring scientist's egalitarian worldview. In contrast, evidence of the heritability of intelligence promoted the attribution of a reactionary worldview (Study 1a).

These inferences extended to other contentious research questions-including the causes of violent behavior and differences in mating strategy-and emerged even when scientists did not react to their findings (Study 1b). Furthermore, every pair of scientists asked the same research question and conducted the same study-differing only in the way their evidence turned out.

How then might the nature of the evidence, a matter beyond the scientists' control, shape perceptions of their worldview?

Scientific reports were interpreted as resulting from directional, as well as accuracy, goals: Participants reported that scientists reached their desired conclusions and not just that they disinterestedly pursued the truth (Studies 2 and 3). They also judged that scientists reporting uncongenial evidence would have been more reactionary earlier on in their careers

(Study 3). In other words, scientists are not seen primarily as drawing normative conclusions from their findings, but as reporting evidence in support of their pre-existing ideology.

Under the assumption that social scientists adopt basic standards of transparency and objectivity in scientific practice-namely, that they would report their findings had they turned 
out differently-it is not clear how this could be. Thus, these results point toward a general disbelief in the objectivity of social science.

This suspicion is in some ways accurate-as revealed by recent demonstrations that professional pressures (Franco, Malhotra, \& Simonovits, 2014) and political homogeneity (Duarte et al., 2015; Jussim et al., 2016) constrain social scientific research, its scope and direction. The present studies point to a related mechanism that may steer the course of social scientific disciplines: Researchers may under-report findings that their peers and the public view as uncongenial, to avoid being misconstrued as reactionary ideologues.

Evolutionary studies provide a case in point: Scientists who adopt an evolutionary approach are perceived as concealing a conservative agenda (Segestrale, 2000), when in fact evolutionary psychologists (Tybur, Miller \& Gangestad, 2007) and anthropologists (Lyle \& Smith, 2012) are substantially more liberal than the general public, and no different ideologically from their departmental peers with other research foci. In conjunction with other recent studies, the present work provides a plausible explanation: Evolutionary methodsmuch like behavioral genetics-explain human behavior in terms of intrinsic, biological mechanisms. Insofar as these scientific claims are viewed as discordant with an egalitarian worldview (Winegard, Clark \& Hasty, 2018), people may be motivated to refute the evidence (Washburn \& Skitka, 2017), doubt its scientific rigor (Colombo, Bucher \& Inbar, 2016) andas shown here- even misattribute a guiding ideological motive.

This lay concept of social and behavioral science leaves researchers between a rock and a hard place when met with potentially uncongenial evidence: Should you look the other way and indirectly sustain ignorance and misinformation, or disseminate the evidence at a foreseeable risk to your reputation and persona? If both options are unpalatable, we should work to dispel this paltry view of social science-through methodological advancements fostering greater objectivity (Washburn, Morgan, \& Skitka, 2015) and transparency (e.g., preregistration and adversarial collaboration), but also through greater philosophical literacy on the distinction between normative values and descriptive facts. 


\section{Acknowledgements}

Cory Clark, Florian Cova, Fiery Cushman, Lee Jussim, Joshua Knobe, Manuel de Pinedo, Simine Vazire, and Neftalí Villanueva provided valuable feedback on earlier drafts of this manuscript.

\section{References}

Bear, A., \& Knobe, J. (2016). Normality: Part descriptive, part prescriptive. Cognition.

Coleman, J. M., \& Hong, Y. Y. (2008). Beyond nature and nurture: The influence of lay gender theories on self-stereotyping. Self and Identity, 7(1), 34-53.

Colombo, M., Bucher, L., \& Inbar, Y. (2016). Explanatory judgment, moral offense, and value-free science. An empirical study. Review of Philosophy and Psychology, 7: 743-763.

Dar-Nimrod, I., \& Heine, S. J. (2011). Genetic essentialism: on the deceptive determinism of DNA. Psychological Bulletin, 137(5), 800.

Gauchat, G. (2012). Politicization of science in the public sphere: A study of public trust in the United States, 1974 to 2010. American sociological review, 77(2), 167-187.

Haider-Markel, D. P., \& Joslyn, M. R. (2008). Beliefs about the origins of homosexuality and support for gay rights: An empirical test of attribution theory. Public Opinion Quarterly, 72(2), 291-310.

Hume, D. (1739). A Treatise of Human Nature.

Imai, K., Keele, L., \& Tingley, D. (2010). A general approach to causal mediation analysis. Psychological methods, 15(4), 309.

Kagan, S. (1998). Normative ethics. Westview Press.

Kunda, Z. (1990). The case for motivated reasoning. Psychological bulletin, 108(3), 480.

Lyle, H. F., \& Smith, E. A. (2012). How conservative are evolutionary anthropologists?. Human Nature, $1-17$.

Nisbet, E. C., Cooper, K. E., \& Garrett, R. K. (2015). The partisan brain: How dissonant science messages lead conservatives and liberals to (dis) trust science. The ANNALS of the American Academy of Political and Social Science, 658(1), 36-66.

Pronin, E., Lin, D. Y., \& Ross, L. (2002). The bias blind spot: Perceptions of bias in self versus others. Personality and Social Psychology Bulletin, 28(3), 369-381.

Pronin, E. (2007). Perception and misperception of bias in human judgment. Trends in cognitive sciences, 11(1), 37-43.

Putnam, H. (2002). The collapse of the fact/value dichotomy and other essays. Harvard University Press. ISBN 0-674-01380-8.

Rutjens, B. T., Sutton, R. M., \& van der Lee, R. (2017). Not all skepticism is equal: Exploring the ideological antecedents of science acceptance and rejection. Personality and Social Psychology Bulletin, 0146167217741314.

Segerstrale, U. (2000). Defenders of the truth: The battle for science in the sociobiology debate and beyond.

Stevenson, C. L. (1944). Ethics and language. Yale University Press.

Suhay, E., Brandt, M. J., \& Proulx, T. (2017). Lay Belief in Biopolitics and Political Prejudice. Social Psychological and Personality Science, 8(2), 173-182.

Tingley, D., Yamamoto, T., Hirose, K., Keele, L., \& Imai, K. (2014). Mediation: R package for causal mediation analysis.

Tybur, J. M., Miller, G. F., \& Gangestad, S. W. (2007). Testing the controversy. Human Nature, 18(4), 313-328.

Washburn, A. N., Morgan, G. S., \& Skitka, L. J. (2015). A checklist to facilitate objective hypothesis testing in social psychology research. Behavioral and Brain Sciences, 38.

Washburn, A. N., \& Skitka, L. J. (2017). Science denial across the political divide: Liberals and conservatives are similarly motivated to deny attitude-inconsistent science. Social Psychological and Personality Science, 1948550617731500.

Weber, M. (1904). The methodology of the social sciences.

Winegard, B. M., Clark, C. J., \& Hasty, C. R. (2018) Equalitarianism: A source of liberal bias. Manuscript in preparation. 